\title{
Friction-wear Properties and Mechanism of Hard Facing Pairs of SiC and WC
}

\author{
YAO Xiu-Min, WANG Xiao-Jie, LIU Xue-Jian, CHEN Zhong-Ming, HUANG Zheng-Ren \\ (The State Key Laboratory of High Performance Ceramics and Superfine Microstructure, \\ Shanghai Institute of Ceramics, Chinese Academy of Sciences, Shanghai 201899, China)
}

\begin{abstract}
Sliding friction-wear properties of pressurelessly solid-state-sintered silicon carbide ceramics (SSiC) and liquid-phase-sintered SiC ceramics (LPSiC) pairing with tungsten carbide (WC) were researched under the frictions with or without lubrication. Under dry friction, as compared to LPSiC/WC pairs, SSiC/WC pairs have higher friction coefficient $(\mu)$ and less mass loss $(\Delta m)$ due to SSiC ceramics have larger particle size and higher hardness. The surface topography of worn area was detected by SEM companying with elements mapping and micro-area XRD technology. The micro plough cut and micro fracture led to the wear of SiC ceramics. Its fatigue damage led to the wear of WC materials. The grinding-out WC grains were oxidized to amorphous $\mathrm{WO}_{3}$ phase due to the friction heat generated in the friction. Under the wet friction with water as lubrication, as compared to SSiC/WC pairs, LPSiC/WC pairs have higher friction coefficient and less mass losses. Whether under dry friction or wet friction, the pairs with $\mathrm{SiC}$ ceramics as the fixed materials have lower $\mu$ and $\Delta m$ than those with $\mathrm{SiC}$ ceramics as the rotated materials.
\end{abstract}

Key words: hard facing; sliding wear; friction pairs; surface topography; wear modeling

Silicon carbide (SiC) has been used as abrasive and seal materials, due to its unique properties, such as low density, high strength, high thermal conductivity, high hardness, high elastic modulus, excellent thermal shock resistance and superior chemical inertness. In order to ensure the safety of the engineering use, the frictionwear properties of $\mathrm{SiC}$ ceramics must be investigated. Microstructure engineering has been proved to be an effective strategy to improve the silding-wear resistance of polycrystalline structure ceramics ${ }^{[1-4]}$.

In recent years, pressurelessly sintered silicon carbide (PLS SiC) ceramics developed as a new kind of seal materials due to its high strength, good oxidation resistance and excellent chemical resistance. It can be submerged in the corrosive environments, subjected to extreme wear and abrasive conditions, and exposed to the temperatures exceeding $1400{ }^{\circ} \mathrm{C}$. There are two kinds of PLS SiC ceramics, one is solid-state-sintered $\mathrm{SiC}$ ceramics $(\mathrm{SSiC})$, which are usually prepared by adding B-C as sintering aids, the other is liquid-phase-sintered $\mathrm{SiC}$ ceramics (LPSiC), which are usually fabricated by adding $\mathrm{Al}_{2} \mathrm{O}_{3}-\mathrm{Y}_{2} \mathrm{O}_{3}$ as sintering aids ${ }^{[5-6]}$. The different composition and microstructure endow them with different properties including the friction properties.
Sang, et $a l^{[7]}$ researched the friction properties of reaction-sintered $\mathrm{Si} / \mathrm{SiC}$ paring with $\mathrm{Si} / \mathrm{SiC}-\mathrm{Ni}$ materials or themselves in the temperature range of $15-600{ }^{\circ} \mathrm{C}$. The results showed that the friction properties of the $\mathrm{Si} / \mathrm{SiC}$ could be improved by addition of Ni. Sasaki, et $a l^{[8]}$ indicated the surrounding atmosphere affected the friction and wear of LPSiC ceramics, such as humid air or water, the results revealed that the wear rate of $\mathrm{SiC}$ decreased with increase in relative humidity. Lopez, et $a l^{[9-11]}$ found that the friction properties of LPSiC ceramics paring with $\mathrm{Si}_{3} \mathrm{~N}_{4}$ ball were influenced by the $\mathrm{SiC}$ particle size, the content of intergranular phase, the internal tensile residual stress and hardness. Cho, et al ${ }^{[12]}$ researched the wear and wear transition of $\mathrm{HP} \mathrm{SiC}$ and HPLP SiC-TiB 2 ceramics paring with $\mathrm{SiC}$ ball, the results showed that the wear behavior of them were influenced by the grain boundary strength. Llorente, et $a l^{[13]}$ researched the dry tribological performance of graphene/ silicon carbide composites paring with silicon nitride balls. The result showed that, compared with monolithic $\mathrm{SiC}$, the graphene nanoplatelets (GNPs) can improve wear resistance because it can form an adhered lubricating and protecting tribofilm in the wear process. Lafon-Placette, et $a l^{[14]}$ researched tribological properties 
of $\mathrm{SiC} / \mathrm{SiC}$ and $\mathrm{SiC} / \mathrm{C}$ pairs using a ring-on-ring device under dry friction, the wear mechanisms were found to be driven by cracking process and oxidation.

In recent years, in some harsh operation conditions, especially high rotation speed and high temperature system, the mechanical seal tends to be hard-face to hard-face seal due to their excellent wear resistance and long service life, such as, $\mathrm{SiC} / \mathrm{WC}$ pairs. Until now, there are few research reports on the sealing properties and friction properties of those pairs.

In this work, we focused on the friction-wear properties of $\mathrm{SiC} / \mathrm{WC}$ pairs. The properties and microstructure of the materials were analyzed. The friction-wear properties, friction surface and friction mechanism of them were also discussed.

\section{Experimental procedure}

\subsection{Samples preparations}

$\mathrm{SSiC}$ ceramics were prepared with $96.4 \mathrm{wt} \% \alpha$-SiC powders $\left(D_{50}=0.5 \mu \mathrm{m}\right.$, SIKA TECH., Lillesand, Norway), $3.0 \mathrm{wt} \%$ carbon black and $0.6 \mathrm{wt} \%$ boron carbide particles as raw materials. The raw materials were ball milled with ethanol as media, dried at $60{ }^{\circ} \mathrm{C}$. After being meshed, the powders were died pressed at $40 \mathrm{MPa}$, cold isostaticly pressed at $200 \mathrm{MPa}$ to fabricate green samples, then the as-prepared specimens were sintered at $2150{ }^{\circ} \mathrm{C}$ for $1 \mathrm{~h}$ to obtain the ceramics.

LPSiC ceramics were prepared with $93 \mathrm{wt} \% \alpha-\mathrm{SiC}$ powders, $3.12 \mathrm{wt} \% \mathrm{Al}_{2} \mathrm{O}_{3}$ pwders (Fenghe Ceramic Co., Ltd., China) and $3.88 \mathrm{wt} \% \mathrm{Y}_{2} \mathrm{O}_{3}$ powders (Yuelong Chemical Co., Ltd., China) as raw materials. The procedure to fabricate LPSiC ceramics was the same with that of $\mathrm{SSiC}$ ceramics except that they were finally sintered at $1930{ }^{\circ} \mathrm{C}$ for $1 \mathrm{~h}$.

The WC materials (N200, 8wt\% $9 \mathrm{wt} \% \mathrm{Ni}-0.8 \sim 1.2 \mathrm{wt} \%$ $(\mathrm{Cr}+\mathrm{Mo})-89.8 \mathrm{wt} \% \sim 91.2 \mathrm{wt} \%$ WC) were provided by KLT Carbide Co. Ltd., Sichuan, China, which were fabricated by gas pressure sintering method.

The as-sintered samples were machined into rectangular blocks with a dimension of $6 \mathrm{~mm} \times 7 \mathrm{~mm} \times 30 \mathrm{~mm}$ and rings with a dimension of internal diameter $\phi 16 \mathrm{~mm}$ and external diameter $\phi 40 \mathrm{~mm}$. And the thickness of the rings was $10 \mathrm{~mm}$. The surfaces of the bars were polished using polishing machinery with diamond slurries.

\subsection{Test and characterization}

The bulk densities of the samples were measured by Archimedes method using distilled water as immersing medium. The Vickers' hardness $\left(H_{\mathrm{v}}\right)$ of the samples was measured on the polished surfaces by Vickers indentation (Wilson-Wolpert Tukon 2100B, Canton, MA) using a load of $3 \mathrm{~kg}$. Rockwell hardness (HRA) of the samples was tested on the polished surfaces by Rockwell indentation (Wilson-2000, Canton, MA) using a load of $60 \mathrm{~kg}$. Fracture toughness $\left(K_{\mathrm{IC}}\right)$ of the samples was calculated by the Vickers indentation method on the basis of the equation proposed by Niihara, et $a l^{[15]}$. The worn areas and the chemical composition of the samples were investigated by scanning electron microscope (SEM, JXA-8100, JEOL, Japan) with an energy dispersive spectrometer. The debris phases on the surface of the friction surface were determined by micro-area XRD technology (Bruker D8 DISCOVER X-Ray, Bruker Corp., Germany).

The friction test was performed on a ring-block friction testing machine (MM200, Jinan test machine factory, China). During the friction, the ring was rotated and the block was fixed. In the present study, four groups of samples were tested without lubrication (dry friction) or with water as lubrication in every pairs $(\Phi \mathrm{WC} / \mathrm{SSiC}$, $\Phi \mathrm{WC} / \mathrm{LPSiC}, \Phi \mathrm{SSiC} / \mathrm{WC}, \Phi \mathrm{LPSiC} / \mathrm{WC})$. The rotation speed and load were $400 \mathrm{r} / \mathrm{min}(0.82 \mathrm{~m} / \mathrm{s})$ and $196 \mathrm{~N}$, respectively. Three pairs of samples were tested in every friction condition. The specimens were cleaned before and after the tests by immersing in acetone with agitation in an ultrasonic bath for $20 \mathrm{~min}$ to calculate the weight loss during the friction process.

\section{Results and discussion}

Table 1 shows the properties of the used materials. It can be clearly seen that the relative density of these three kinds of materials are over $99 \%$, which means that the samples are highly densified and have few visible pores (seen in Fig. 1). By comparison, the SSiC ceramics have the lowest fracture toughness and highest hardness, the WC materials have the highest fracture toughness and lowest hardness, and the fracture toughness and hardness of LPSiC ceamics are in the median.

Table 1 Properties of the prepared materials

\begin{tabular}{cccccc}
\hline & Composite $/ \mathrm{wt} \%$ & Grain size $/ \mu \mathrm{m}$ & Relative density $/ \%$ & Fracture toughness $/\left(\mathrm{MPa} \cdot \mathrm{m}^{1 / 2}\right)$ & $\mathrm{HV}$ \\
3.0 & $/ \mathrm{GPa}$ & $\mathrm{HRA}$ \\
\hline $\mathrm{SSiC}$ & $96.4 \mathrm{SiC}-3.0 \mathrm{C}-0.6 \mathrm{~B}_{4} \mathrm{C}$ & $3-5$ & $>99$ & $(2.96 \pm 0.20)$ & $(20.78 \pm 0.96)(93.4 \pm 0.1)$ \\
$\mathrm{LPSiC}$ & $93 \mathrm{SiC}-7 \mathrm{YAG}$ & $<2$ & $>99$ & $(3.66 \pm 0.23)$ & $(19.72 \pm 0.52)(92.7 \pm 0.3)$ \\
& $89.9-91.2 \mathrm{WC}-8-9 \mathrm{Ni}-$ & $<3$ & $>99$ & $(6.65 \pm 0.29)$ & $(14.86 \pm 0.46)(90.4 \pm 0.1)$ \\
$\mathrm{WC}$ & $0.8-1.2(\mathrm{Cr}+\mathrm{Mo})$ & & & & \\
\hline
\end{tabular}



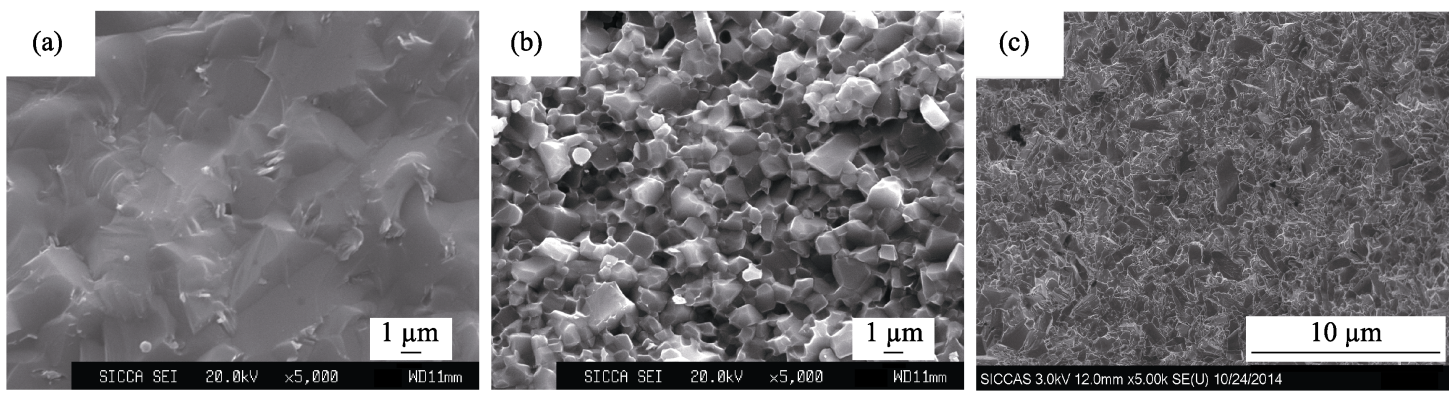

Fig. 1 Fracture microstructures of three kinds of samples

(a) SSiC materials; (b) LPSiC materials; (c) WC materials

Figure 1 shows the fracture surface microstructures of these three kinds of samples. It can be seen that the fracture mode of $\mathrm{SSiC}$ cermics is complete transgranular fracture, showing the strong interface bonding between the $\mathrm{SiC}$ grains. Compared with the other two kinds of materials, SSiC ceramics were obtained at higher temperature via a solid-state sintering route, so $\mathrm{SSiC}$ ceramics had bigger grain sizes of about $3-5 \mu \mathrm{m}$. Both of them led to the higher hardness and lower fracture toughness of SSiC ceramics. It can be also seen that the fracture mode of LPSiC ceramics is mainly intergranular fracture because of the interface YAG phases between $\mathrm{SiC}$ grains, which were formed during the liquid-phase-sintering process and led to the weak interface bonding between the $\mathrm{SiC}$ grains. And the $\mathrm{SiC}$ particle sizes in LPSiC ceramics are about $1-2 \mu \mathrm{m}$ due to their lower sintering temperature. Interface phase, intergranular fracture mode and smaller particle sizes led to the lower hardness and higher fracture toughness of LPSiC ceramics. In the WC samples, the grain sizes of WC particles are smaller than $3 \mu \mathrm{m}$, the highest fracture toughness and lowest hardness of the samples were obtained due to their metal features.

Table 2 and 3 show the friction properties of different $\mathrm{SiC} / \mathrm{WC}$ pairs. Under dry friction condition, all friction pairs have higher friction coefficient $(\mu)$. However, compared with the pairs containing SSiC ceramics, the pairs containing LPSiC ceramics have lower friction coefficient and higher friction mass loss. It is well documented that coarser ceramics have poorer slidingwear property ${ }^{[16-17]}$, in which the wear-mechanism transition occurs sooner from initial mild wear controlled by dislocation plasticity to severe fracture-controlled wear ${ }^{[12]}$. The $\mathrm{SiC}$ grain sizes in the $\mathrm{SSiC}$ ceramics are bigger than those in the LPSiC ceramics, which leads to the quicker friction mechanism transition from mild wear to severe fracture-controlled wear, which is in consistent with Sang's results ${ }^{[7]}$ on $\mathrm{SiC}-\mathrm{Si}$ ceramics. At the same time, the stronger grain bonding between $\mathrm{SiC}$ grains in the $\mathrm{SSiC}$ ceramics leads the fracture occurred inside the grains, both of which lead to the higher $\mu$ of those containing SSiC pairs. From Table 1, the hardness of LPSiC ceramics is lower than that of $\mathrm{SSiC}$ ceramics, and the former contains a large amount of YAG phases, which have lower hardness $(\sim 15 \mathrm{GPa})^{[18]}$. Both of them led to higher mass losses of LPSiC ceramics in the friction.

From Table 3, it can be seen that, with water as lubrication, the $\mu$ of all pairs are lower than 0.1 and the mass loss can be negligible. Meanwhile, the $\mu$ of LPSiC/WC pairs is higher than that of SSiC/WC pairs, which is contrary to that of dry friction.

Table 2 Friction properties of different pairs of SiC/WC under dry friction

\begin{tabular}{cccc}
\hline Materials of ring/block & Friction coefficient & $(\Delta m / m)$ of block $/ \%$ & $(\Delta m / m)$ of ring/\% \\
\hline$\Phi \mathrm{SSiC} / \mathrm{WC}$ & $(0.70 \pm 0.02)$ & $(-0.0029 \pm 0.0001)$ & 0 \\
$\Phi \mathrm{WC} / \mathrm{SSiC}$ & $(0.66 \pm 0.09)$ & $(-0.0009 \pm 0.0004)$ & $(-0.0036 \pm 0.0023)$ \\
$\Phi \mathrm{LPSiC} / \mathrm{WC}$ & $(0.63 \pm 0.01)$ & $(-0.0041 \pm 0.0005)$ & $(-0.0038 \pm 0.0009)$ \\
$\Phi \mathrm{WC} / \mathrm{LPSiC}$ & $(0.57 \pm 0.01)$ & $(-0.0034 \pm 0.0008)$ & $(-0.0105 \pm 0.0019)$ \\
\hline
\end{tabular}

Table 3 Friction properties of different pairs of $\mathrm{SiC} / \mathrm{WC}$ with water as lubrication

\begin{tabular}{cccc}
\hline Materials of ring/block & Friction coefficient & $(\Delta m / m)$ of block $/ \%$ & $(\Delta m / m)$ of ring $/ \%$ \\
\hline$\Phi S S i C / W C$ & $(0.031 \pm 0.001)$ & $(-0.0004 \pm 0.0001)$ & $(-0.0010 \pm 0.0001)$ \\
$\Phi \mathrm{WC} / \mathrm{SSiC}$ & $(0.018 \pm 0.004)$ & $(-0.0004 \pm 0.0001)$ & $(+0.0004 \pm 0.0004)$ \\
$\Phi \mathrm{LPSiC} / \mathrm{WC}$ & $(0.093 \pm 0.004)$ & $(-0.0002 \pm 0.0001)$ & $(-0.0008 \pm 0.0001)$ \\
$\Phi \mathrm{WC} / \mathrm{LPSiC}$ & $(0.020 \pm 0.007)$ & $(-0.0004 \pm 0.0001)$ & $(-0.0003 \pm 0.0006)$ \\
\hline
\end{tabular}


From Table 2 and 3, in SiC/WC pairs, when $\mathrm{SiC}$ ceramics (both $\mathrm{SSiC}$ and $\mathrm{LPSiC}$ ceramics) were as fixed friction materials (as blocks), the $\mu$ of the pairs is lower than that with WC materials as fixed friction materials. Under fry friction, the wear rate of the former is higher than that of the latter. Therefore, in order to decrease $\mu$, it is a good option to choose the $\mathrm{SiC}$ ceramics as the fixed friction materials; in order to decrease the wear, it would be better to choose WC materials as the fixed friction materials in the $\mathrm{SiC} / \mathrm{WC}$ friction pairs.

Figure 2 shows the wear face microstructure of the blocks in different $\mathrm{WC} / \mathrm{SiC}$ pairs under dry friction. Comparing with $\mathrm{SiC}$ ceramics as the fixed blocks, the friction marks of $\mathrm{WC}$ materials as the fixed blocks are fewer, and there are no obvious $\mathrm{SiC}$ materials on the surfaces of WC blocks (seen in Fig. 2(a) and (b)). However, there is a lot of debris on the surface of SiC ceramics (seen in Fig. 2(c) and (d)). Both of them show that the wear rate of the pairs with $\mathrm{SiC}$ as the fixed friction materials is higher than that of the pairs with $\mathrm{WC}$ as the fixed friction materials, which is in agreement with the result in Table 2. It can be also seen that no WC particles are pulled out on the surface of WC materials. Because the friction test is ring-to-block mode, the friction heat was mainly produced in the friction surface and stored in the block, which led to the severe wear of the block. When WC materials were used as blocks, plastic deformation took place continuously in the WC materials due to its high toughness. In the end, cracks were induced by fatigue damage (seen in Fig. 2(b)) and the roughness of WC materials increased, which led to the increase of friction coefficient. With $\mathrm{SiC}$ materials as the fixed blocks, a lot of debris were observed on the over worn surfaces, which demonstrated that $\mathrm{SiC}$ ceramics or $\mathrm{WC}$ materials were worn down.
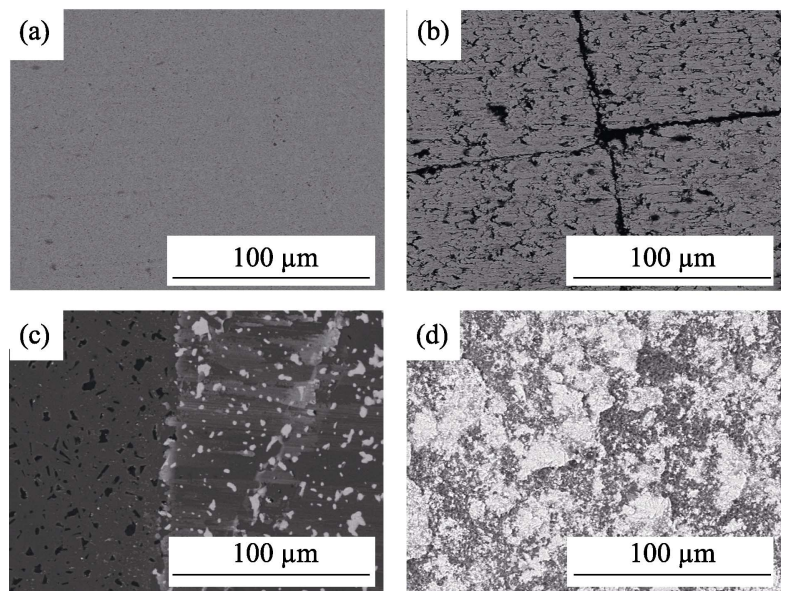

Fig. 2 Wear face microstructures of the blocks in different $\mathrm{WC} / \mathrm{SiC}$ pairs without lubrication

(a) $\Phi \mathrm{SSiC} / \mathrm{WC}$; (b) $\Phi \mathrm{LPSiC} / \mathrm{WC}$; (c) $\Phi \mathrm{WC} / \mathrm{SSiC}$; (d) $\Phi \mathrm{WC} / \mathrm{LPSiC}$
Figure 3 shows the worn face microstructure of $\mathrm{SiC}$ samples in different pairs. From Fig. 3(a), cracks are detected in SSiC ceramics after dry friction test, while no cracks are found in the LPSiC ceramics in the detected area. Usually for the same materials, the tendency of crack's formation is stronger in the samples of fine particles than that of coarse ones, because the peak stress could be limited due to a uniform distribution of the stress for the coarse particles ${ }^{[19]}$. In the experiments, LPSiC ceramics have higher fracture toughness, which leads them have good resistance to crack propagation. Therefore, no cracks are observed in the worn face of LPSiC ceramics. After being rubbed with WC, the obvious scratches are observed on the worn surface of SSiC blocks along the friction direction, and large amounts of debris (the white parts in Fig. 3) were produced. At the same time, almost all $\mathrm{SiC}$ particles are broken in the worn area of SSiC ceramics (shown by the inset figure in Fig. 3(a)). It can be concluded that the micro plough cut and micro fracture existed in the friction process of SSiC ceramics. From Fig. 3(b), it can be seen that there is more debris on the surface of LPSiC samples than that on the surface of SSiC samples, which is in agreement with the data in Table 2. No obvious scratches and grain fracture were observed on the surface of LPSiC samples due to the large amount of debris. However, from the magnified macrostructure in the Fig. 3(b), the grain pullout is detected, which is attributed to the weak interface bonds in LPSiC ceramics, and the particle sizes of the most debris are nanometers. From Fig. 3(c) and (d), with water as lubrication, there are slight scratch marks and a few debris on the worn faces of $\mathrm{SiC}$ ceramics, which means $\mathrm{SiC}$ ceramics have good lubrication performance.
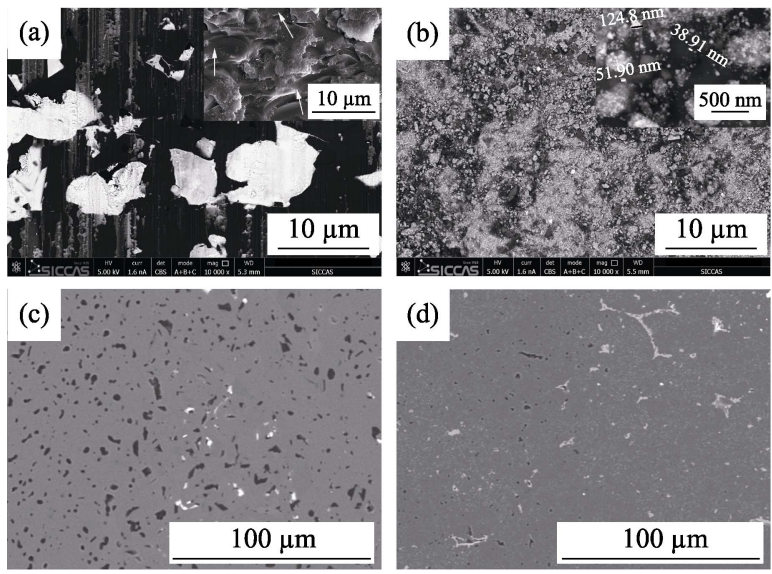

Fig. 3 Wear face microstructures of SiC samples in different pairs

(a) $\Phi \mathrm{WC} / \mathrm{SSiC}$ under dry friction; (b) $\Phi \mathrm{WC} / \mathrm{LPSiC}$ under dry friction; (c) $\Phi \mathrm{WC} / \mathrm{SSiC}$ with water as lubrication; (d) $\Phi \mathrm{WC} / \mathrm{LPSiC}$ with water as lubrication 
Figure 4 shows the EDS mapping of the worn surface of SSiC blocks in $\Phi \mathrm{WC} / \mathrm{SSiC}$ pairs. Obviously, the $\mathrm{Si}$ element matches with $\mathrm{C}$ element very well in these areas. It can be also seen that $\mathrm{W}$ element matches quite well with $\mathrm{O}$ element, which indicated that $\mathrm{WO}_{3}$ was formed in the wear area. The existence of $\mathrm{WO}_{3}$ indicated that oxidative wear occurred in the dry friction. The same phenomena were observed in the $\Phi \mathrm{WC} / \mathrm{LPSiC}$ samples. During the friction process, the $\mathrm{SiC}$ particles were broken in SSiC samples and pulled out in LPSiC ceramics under the applied force, which were as the abrasive to wear the samples and produce the debris. From Fig. 3(b), the sizes of $\mathrm{WO}_{3}$ particles were lower than $200 \mathrm{~nm}$. Smaller debris size and a large amount of friction heat led to the oxidation of $\mathrm{WC}$ debris into $\mathrm{WO}_{3}$. And the soft $\mathrm{WO}_{3}$ phase is beneficial to reduce the friction efficient.

Figure 5 shows the micro-area XRD pattern of the worn surface of SSiC blocks in $\Phi \mathrm{WC} / \mathrm{SSiC}$ pairs under dry condition. The result showed that the debris consists of $\mathrm{SiC}$ as a major phase and graphite as the co-existence phase. No $\mathrm{WC}, \mathrm{WO}_{3}$ and $\mathrm{SiO}_{2}$ phases are detected. Both of them indicated that all abrasive $\mathrm{WC}$ phases were transferred to $\mathrm{WO}_{3}$ (seen in Fig. 4), which existed as an amorphous phase. At the same time, the peaks of $\mathrm{SiC}$ phase were similar to the original $\mathrm{SSiC}$ ceramics, which meant few $\mathrm{SiC}$ phase existed in the debris. Therefore, the $\mathrm{X}$-ray diffraction pattern of $\mathrm{SiC}$ phases were from the original SSiC ceramics. The same phenomenon was observed in $\Phi \mathrm{WC} / \mathrm{LPSiC}$ pairs.

\section{Conclusions}

Friction-wear properties of different $\mathrm{SiC} / \mathrm{WC}$ pairs were investigated under dry friction conditions or with water as lubrication. Compared to LPSiC/WC pairs, the $\mathrm{SSiC} / \mathrm{WC}$ pairs have higher friction coefficient and less mass loss because SSiC ceramics have larger particles size and higher hardness. The friction coefficient of the pairs with $\mathrm{SiC}$ ceramics as the fixed friction materials is lower than that with WC materials as the fixed friction materials. The wear rate of the former is higher than that of the latter due to the lower hardness of WC. The WC debris was oxidized to amorphous $\mathrm{WO}_{3}$ phase due to friction heat and the smaller debris sizes.
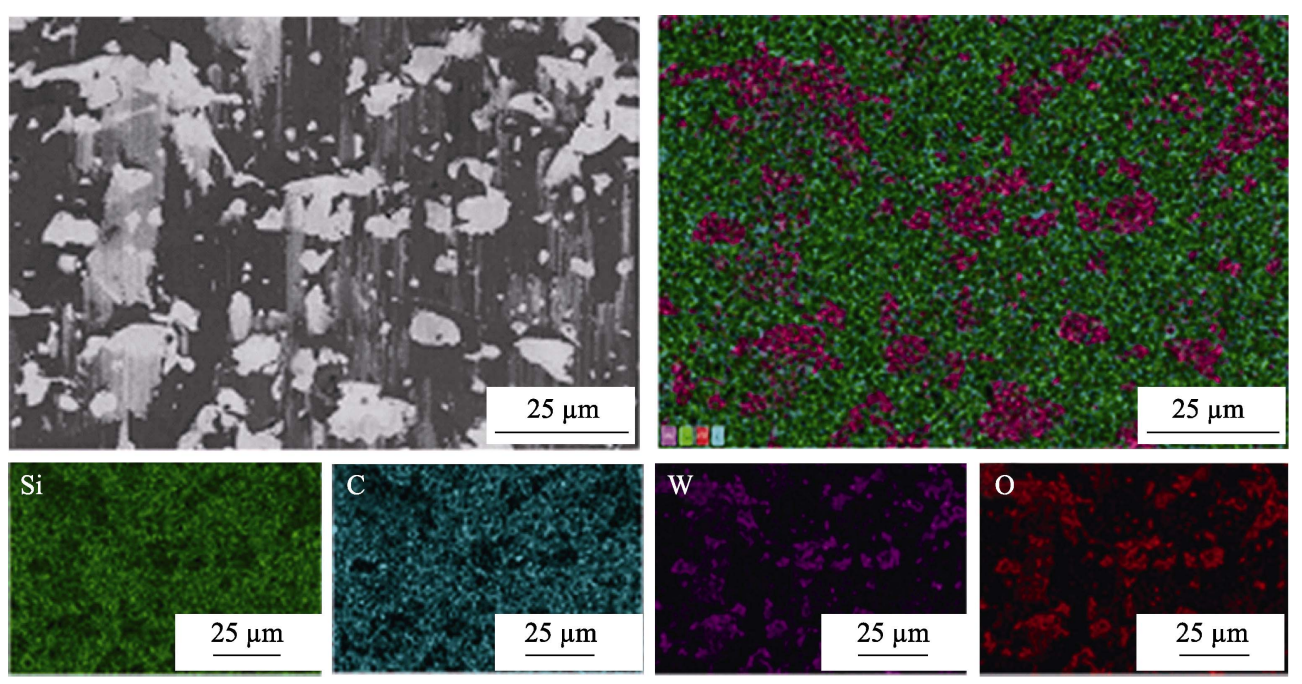

Fig. 4 EDS mapping of the worn surface of SSiC blocks in $\Phi \mathrm{WC} / \mathrm{SSiC}$ pairs

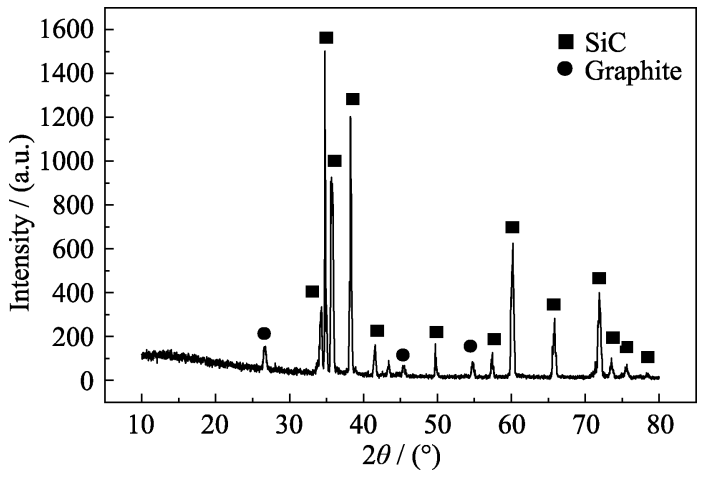

Fig. 5 Micro-area XRD pattern of the worn surface of SSiC blocks in $\Phi \mathrm{WC} / \mathrm{SSiC}$ pairs under dry friction

\section{References:}

[1] BORRERO-LÓPEZ O, ORTIZ AL, GUIBERTEAU F, et al. Effect of microstructure on sliding-wear properties of liquid-phase-sintered $\alpha$-SiC. J. Am. Ceram. Soc., 2005, 88(8): 2159-2163.

[2] BORRERO-LÓPEZ O, ORTIZ AL, GUIBERTEAU F, et al. Slidingwear resistant liquid-phase sintered $\mathrm{SiC}$ processed using $\alpha$-SiC starting powders. J. Am. Ceram. Soc., 2007, 90(2): 541-545.

[3] BORRERO-LÓPEZ O, ORTIZ AL, GUIBERTEAU F, et al. Microstructural design of sliding-wear-resistant liquid-phase-sintered SiC: an overview. J. Eur. Ceram. Soc., 2007, 27(11): 3351-3357.

[4] BORRERO-LÓPEZ O, ORTIZ AL, GUIBERTEAU F, et al. Effect of the nature of the intergranular phase on sliding-wear resistance of liquid-phase-sintered $\alpha$-SiC. Scr. Mater, 2007, 57(6): 505-508. 
[5] ALliEgRO R, COFFIN L, TINKLEPAUGH J. Pressure-sintered silicon carbide. J. Am. Ceram. Soc., 1956, 39(11): 386-389.

[6] OMORI M, TAKEI H. Pressureless sintering of SiC. J. Am. Ceram. Soc., 1982, 65(6): c92-c92.

[7] SANG K Z, JIN Z H. Unlubricated friction of reaction-sintered silicon carbide and its composite with nickel. Wear, 2000, 246(1/2): 34-39.

[8] SASAKI S. The effect of the surrounding atmosphere on the friction and wear of alumina, zirconia, silicon carbide and silicon nitride. Wear, 1989, 134(1): 185-200.

[9] BORRERO-LÓPEZA O, ORTIZA AL, GUIBERTEAUA F, et al. Effect of liquid-phase content on the contact-mechanical properties of liquid-phase-sintered $\alpha$-SiC. J. Eur. Ceram. Soc., 2007, 27(6): 2521-2527.

[10] BORRERO-LÓPEZA O, ORTIZA AL, GUIBERTEAUA F. Improved sliding-wear resistance in situ-toughened silicon carbide. $J$. Am. Ceram. Soc., 2005, 88(12): 3531-3534.

[11] CIUDAD E, BORRERO-LÓPEZ O, RODRÍGUEZ-ROJAS F, et al. Effect of intergranular phase chemistry on the sliding-wear resistance of pressureless liquid-phase-sintered $\alpha$-SiC. J. Euro. Ceram. Soc., 2012, 32(2): 511-516.

[12] CHO S J, UM C D, KIM S S. Wear and wear transition in silicon carbide ceramics during sliding. J. Am. Ceram. Soc., 1996, 79(5):
$1247-1251$.

[13] LLORENTE J, ROMAN-MANSO B, MIRANZO P, et al. Tribological performance under dry sliding conditions of graphene/silicon carbide composites. J. Euro. Ceram. Soc., 2016, 36(3): 429-435.

[14] LAFON-PLACETTE S, DELBE K, DENAPE J, et al. Tribological characterization of silicon carbide and carbon materials. J. Euro. Ceram. Soc., 2015, 35(4): 1147-1159.

[15] NIIHARA K, MORENA R, HASSELMAN D. Evaluation of $K_{\text {IC }}$ of brittle solids by the indentation method with low crack-to-indent ratios. J. Mater. Sci. Lett., 1982, 1(1): 13-16.

[16] CHO S J, HOCKEY B J, LAWN B R, et al. Grain-size and $\mathrm{R}$-curve effects in the abrasive wear of alumina. J. Am. Ceram. Soc., 1989, 72(7): 1249-1252.

[17] CHO S J, UM C D, KIM S S. Wear and wear transition mechanism in silicon carbide during sliding. J. Am. Ceram. Soc., 1995, 78(4): 1076-1078.

[18] DEWITH G, PARREN J. Translucent $\mathrm{Y}_{3} \mathrm{Al}_{5} \mathrm{O}_{12}$ ceramics-mechanicalproperties. Solid State Ionics, 1985, 16(1-4): 87-93.

[19] SANG K Z, LIU L, JIN Z H. Improvements on dry friction and wear properties for reaction-sintered silicon carbide by the matching size of SiC particles. Mater and Design, 2007, 28(2): 735-738.

\title{
碳化硅/碳化铇硬面密封摩擦副的摩擦磨损性能和机理研究
}

\author{
姚秀敏, 王晓洁, 刘学建, 陈忠明, 黄政仁 \\ (中国科学院 上海硅酸盐研究所, 高性能陶瓷和超微结构国家重点实验室, 上海 201899)
}

摘 要: 实验研究了干摩擦和水润滑条件下, 常压固相烧结碳化硅陶瓷(SSiC)及常压液相烧结碳化硅陶瓷(LPSiC)分 别与碳化铇(WC)组成的硬面配对摩擦副的滑动摩擦磨损性能。在干摩擦条件下，与 LPSiC/WC 摩擦副相比, SSiC 陶瓷由于具有更大的晶粒尺寸和硬度, 导致 $\mathrm{SSiC} / \mathrm{WC}$ 摩擦副具有更大的摩擦系数和更小的磨损量。磨损区域的 SEM 形貌结合面扫描分析、微区 XRD 分析结果表明：微犁沟和微断裂导致 SiC 陶瓷的磨损，疲劳损伤导致 WC 材 料的磨损, 而摩擦过程产生的摩擦热导致磨出的 $\mathrm{WC}$ 颗粒氧化成无定型 $\mathrm{WO}_{3}$ 。在水润滑条件下, 与 $\mathrm{SSiC} / \mathrm{WC}$ 摩擦 副相比, LPSiC/WC 摩擦副具有更大的摩擦系数和更低的磨损率。在干摩擦和水润滑条件下, 与 $\mathrm{SiC}$ 陶瓷作为动摩 擦副配对相比, $\mathrm{SiC}$ 陶瓷作为固定摩擦副的摩擦配对具有更小的摩擦系数和质量损失。

关 键 词: 硬面密封; 滑动摩擦; 摩擦副; 表面形貌; 磨损机制

中图分类号: TQ174 文献标识码: A 